\title{
POLYMETHYL METHACRYLATE V.S CAYANOACRYLATE FOR DENTURE TEETH REBONDING
}

\author{
Bassem Mohsen* and Shereen Hashem**
}

\begin{abstract}
Debonded/detached denture teeth is a very common cause for denture failures. Chairside repairs using Polymethylmethacrylate (PMMA) is a technique sensitive and difficult procedure. An alternative adhesive that was quickly recognized was the Cyanoacrylate (CA). CA are solvent free adhesives that cure rapidly when pressed into a thin film between two surfaces. Apart from that, they have clinical applications in medicine, especially as tissue adhesives and sealing materials. Materials and methods: Specimens consisted of acrylic teeth bonded to acrylic denture base. The specimens were divided into two groups; group I for testing bond strength using PMMA and group II for testing bond strength using CA. Results: The lowest mean MPa was seen in group 2 and the difference in $\mathrm{MPa}$ between this group and group 1 was significant. Conclusion: Even though CA appears to be the easier option, its' bond strength for teeth rebonding to denture base is less than that of PMMA.
\end{abstract}

KEYWORDS: Polymethylmethacrylate, Cyanoacrylate, denture teeth, debonding Abbreviations: Polymethylmethacrylate: PMMA; Cyanoacrylate: CA; Megapascal: MPa; Ridge-lap surface area: RLSA.

\section{INTRODUCTION}

The use of denture base resin has revolutionized the dental material sciences ever since their discovery. Polymethyl methacrylate (PMMA), an acrylic resin, was first introduced in 1937 by Dr Walter Wright and is currently the material of choice for the fabrication of removable partial denture and a complete denture. PMMA has several advantages making it an attractive material to use like its` good aesthetics, accurate fit, stability in the oral environment as well as easy laboratory and clinical manipulation. This material however, is not ideal in every respect, PMMA lacks sufficient strength, ductility and viscoelastic behaviour. These drawbacks are reflected clinically in the unresolved problem of denture fracture and the consequent repair costs ${ }^{(1)}$.

Darbar et al. reported that 33\% of the repairs carried out by three laboratories were due to debonded/detached teeth, $29 \%$ were because of

\footnotetext{
* Lecturer of Removable Prosthodontics, Faculty of Oral and Dental Medicine Future University in Egypt

** Lecturer of Dental Material, Faculty of Oral and Dental Medicine Future University in Egypt.
} 
midline fractures which were more commonly seen in the upper dentures and the rest $(38 \%)$ were other types of fracture. Most of the fractures had occurred in the mouth whilst chewing and the majority of dentures were made of acrylic resin while some had some form of strengtheners ${ }^{(2)}$.

Fractures in dentures result from two different types of forces, namely, flexural fatigue and impact. Flexural fatigue occurs after repeated flexing of a material and is a mode of fracture whereby a structure eventually fails after being repeatedly subjected to loads that are so small that one application apparently does nothing detrimental to the component. Teeth debonding particularly in the anterior segment of the dentures is a frequent occurrence and is quite frustrating for both the dentists and the patients. Several approaches have been proposed to combat this problem, from increasing the bond strength during the manufacturing process to the use of convenient yet durable ways for repair( ${ }^{(3)}$.

To increase the life-span and strength of the acrylic dentures, effective bond strength between the acrylic teeth and the denture base is mandatory ${ }^{(4)}$. Multiple variables such as occlusion, tooth/alveolar ridge position, ridge-lap surface area (RLSA) modification of acrylic teeth, types of denture base materials and processing methods may contribute to the bond failure at the acrylic teeth-denture base interface. Numerous laboratory processing related errors affect bonding between acrylic teeth and denture base including improper wax removal from the teeth RLSA, carelessness in the separating medium application, use of insufficient monomer and the polymerization method(5)

It is now well established that the recent advances in processing techniques have improved the tooth/denture shear bond strength. Actually, it is now reported that in several studies the shear bond strength of the tooth/denture exceeds the maximum bite force, exerted by complete denture wearers, $(90 \mathrm{~N})$. Nevertheless, it should be noted that the debonding of denture teeth is still a common incidence. Tooth displacement from the complete denture may occur due to mechanical fatigue from repeated chewing, accidental falling, or by incorrect laboratory technique ${ }^{(6)}$.

Chairside repair options are limited. Conventionally, when a tooth is separated from the denture base, the denture is fixed in the lab using PMMA. This is time-consuming and leaves the denture wearer without the appliance. Chairside repairs using PMMA is a technique sensitive and difficult procedure. An alternative adhesive that was quickly recognized was the Cyanoacrylate. It was first described in 1949. Cyanoacrylates are solvent-free adhesives that cure rapidly when pressed into a thin film between two surfaces. Apart from that, they have clinical applications in medicine, especially as tissue adhesives and sealing materials ${ }^{(7)}$.

The use of cyanoacrylate for rebonding a separated denture tooth has been advertised greatly, it was considered to be a home remedy for fixing a broken denture. Denture wearers however not always have at hand the necessary expertise for the correct use and preparation for the tooth rebonding procedure $^{(8)}$.

The use of cyanoacrylate as a denture fixative was due to its' insolubility, availability and ease of use. Thin layers of cyanoacrylate bonds more effectively than a thicker one that does not cure properly. Cyanoacrylates have their drawbacks as well, they Cyanoacrylate glue has a low shear strength and reports on its toxicity are inconclusive ${ }^{(9)}$.

\section{MATERIALS AND METHODS}

A bar-shaped specimens $4 \times 4 \times 6 \mathrm{~mm}$ were prepared from the molar region of an acrylic upper denture. Each specimen consisted of acrylic teeth bond to the acrylic denture base. The specimens were divided into two groups; group I for testing bond strength using PMMA and group II for testing bond strength using CA. The teeth were separated from the denture base using tensile force. For group I, the neck of acrylic teeth were treated with MMA 
monomer, while for group II, the teeth were treated with CA adhesive. After that, the teeth were bonded to the denture base under constant finger pressure.

\section{Microbars preparation}

Each assembly was mounted on the cutting machine, and sectioned into a series of $1 \mathrm{~mm}$ using the diamond disks. Then, the assembly was rotated $90^{\circ}$ and sectioned longitudinally to get microbars with $1 \mathrm{~mm}^{2}$ cross sectional area.

\section{Mechanical testing}

The test was performed using the universal testing machine with a specially designed attachment jig.
Each specimen was attached to the attachment jig where tensile force with compression mode was applied at a crosshead speed $0.5 \mathrm{~mm} / \mathrm{min}$ until failure. Load at debonding was recorded in Newton $(\mathrm{N})$. The bond strength was recorded as force(load at failure)/ area $\left(1 \mathrm{~mm}^{2}\right)$. (fig. 1$)$

\section{RESULTS}

\section{Stress-strain results}

The lowest mean MPa was observed in group 2 ( 10.25) and the difference in MPa between this group and group 1 was significant, using the student t-test $(\mathrm{p} \leq 0.001)$ (table1 and fig. 1.)

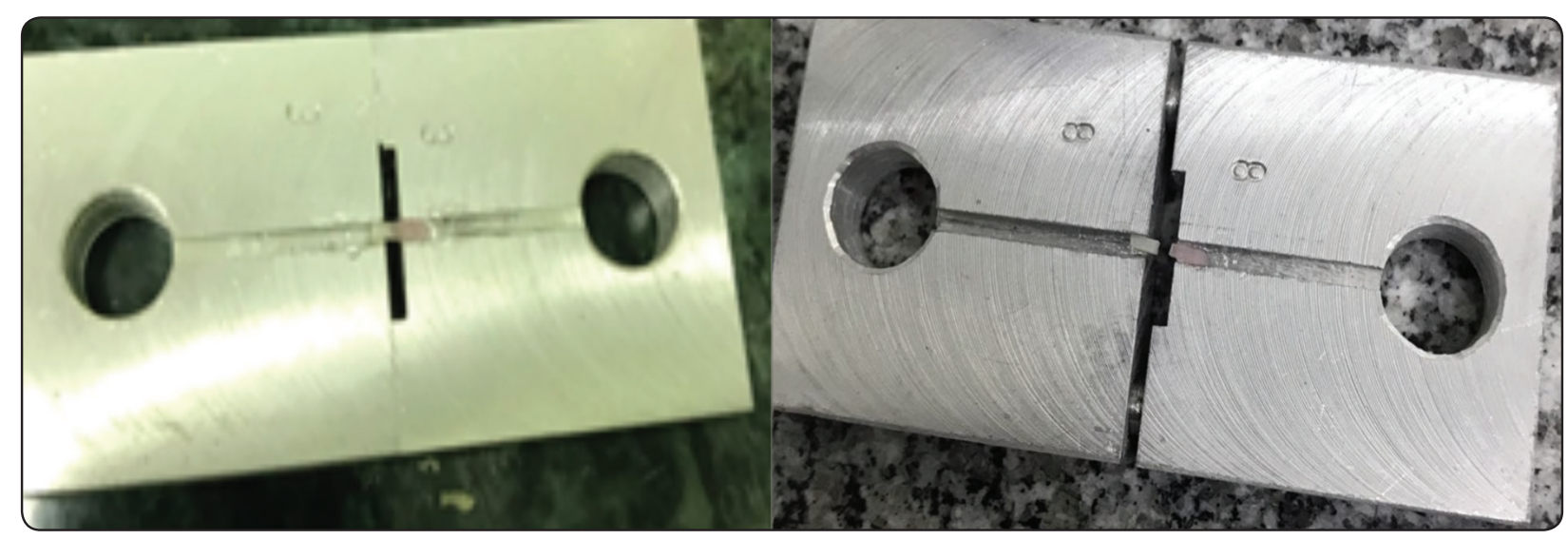

Fig. (1) Attachment Jig before (left) and after (right) testing.

TABLE (1) Stress/strain values (MPa) among the studied groups

\begin{tabular}{|c|c|c|c|c|}
\hline Groups & Mean & $\begin{array}{c}\text { Std. Deviation } \\
( \pm \mathrm{SD})\end{array}$ & t-test & P value \\
\hline Group 1 & 36.92 & 2.99 & \multirow{2}{|c|}{13.374} & $<0.001$ \\
\cline { 1 - 2 } Group 2 & 10.25 & 2.64 & & Highly significant \\
\hline
\end{tabular}




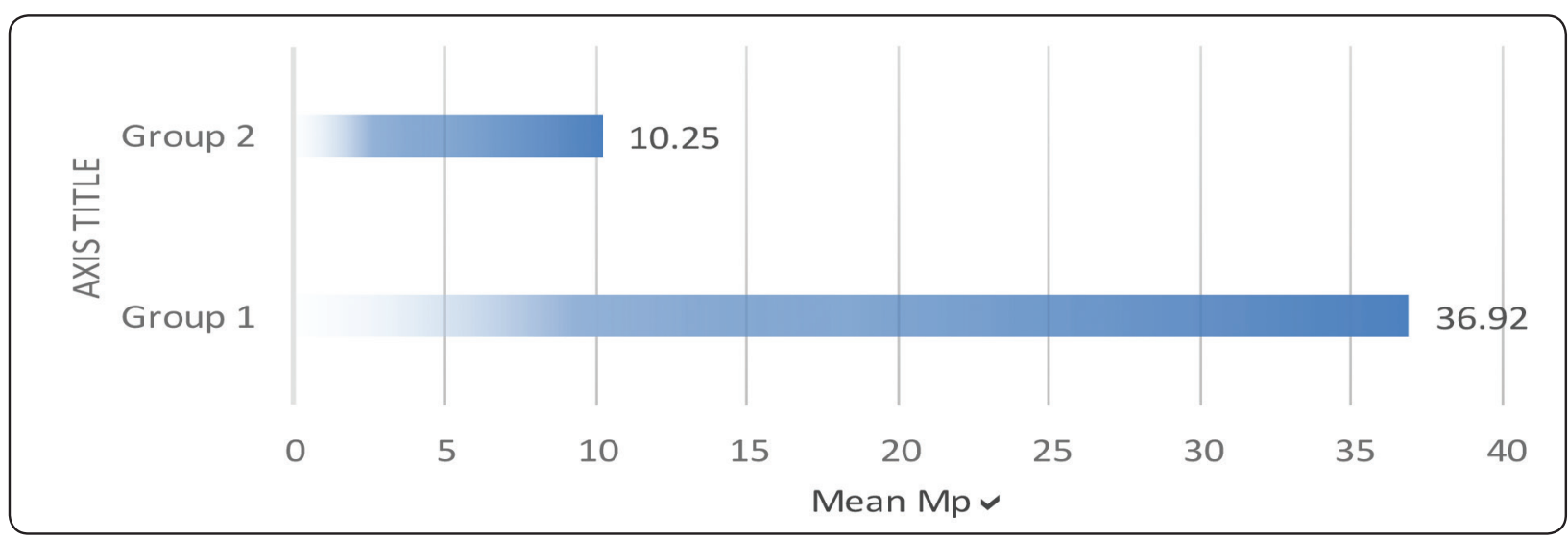

Fig. (2): Bar chart of the mean MPa, for Group 1 and Group 2.

\section{DISCUSSION}

Fracture of denture teeth from the denture base is a common problem associated with dental prosthesis. Studies showed that tooth surfaces treated with chemical agents and mechanical features have the potential to improve the bond strength between cross linked acrylic teeth and acrylic denture base. The present study was conducted to evaluate the bond strength between rebonded acrylic teeth and denture base after treating the teeth with MMA versus treating teeth with cyanoacrylate adhesive. In this study the microtensile bond strength test, created by Sano H. et al, was used. One $\mathrm{mm}^{2}$ microbars were used to decrease the occurrence of internal defects and surface flaws (Sano H, 1994).

The results of the present study demonstrated that treating the debonded acrylic teeth with MMA prior to rebonding teeth to denture base resulted in significantly higher bond strength that using cyanoacrylate adhesive. The high bond strength associated with MMA is in accordance with the results of previous study carried by Saavedra et al, where wetting acrylic teeth with MMA improved the bond strength compared to untreated teeth ${ }^{(9)}$. This improvement in the bond strength might be attributed to the ability of MMA to dissolve the thick cross linked layer of PMMA in acrylic teeth allowing the penetration of MMA and thus improving adhesion with denture base. It was explained by Takahashi et $\mathbf{a l}^{(10)}$ that the strength of the bond depends on the degree of monomer penetration and the strength of the interwoven polymer network formed after that. In addition, Wiebelt et al ${ }^{(11)}$ in their work reported similar findings to that of the present study. They reported that the results may be explained by the fact CA glues have low shear strength and that CA can't fill gaps ${ }^{(12)}$.

\section{CONCLUSIONS}

Cyanoacrylate as a denture fixative is not a good substitute for the traditional Polymethyl Methacrylate.

\section{REFERENCES}

1. Ladha, K., \& Shah, D. (2011). An in-vitro evaluation of the flexural strength of heat-polymerized poly (methyl methacrylate) denture resin reinforced with fibres. The Journal of Indian Prosthodontic Society, 11(4), 215.

2. Meng, G. K., Chung, K. H., Fletcher-Stark, M. L., \& Zhang, H. (2010). Effect of surface treatments and cyclic loading on the bond strength of acrylic resin denture teeth with autopolymerized repair acrylic resin. The Journal of prosthetic dentistry, 103(4), 245-252.

3. Dhiman, R.K., \& Chowdhury, S.R. (2009). Midline fractures in single maxillary complete acrylic vs flexible dentures. Medical Journal Armed Forces India,65(2), 141-145. 
4. Campbell, S. D., Cooper, L., Craddock, H., Hyde, T. P., Nattress, B., Pavitt, S. H., \& Seymour, D. W. (2017). Removable partial dentures: the clinical need for innovation. The Journal of prosthetic dentistry, 118(3), 273-280.

5. Gul, H., Aslam, A., Nayyer, M., \& Kaleem, M. (2017). Possible errors in acrylic denture fabrication leading to teeth-denture base interface failure. Pakistan Oral \& Dental Journal, 37(3), 510-515.

6. Shala, K., Tmava-Dragusha, A., Dula, L., PustinaKrasniqi, T., Bicaj, T., Ahmedi, E., \& Lila, Z. (2018). Evaluation of Maximum Bite Force in Patients with Complete Dentures. Open access Macedonian journal of medical sciences, 6(3), 559.

7. Patil, S.B., Naveen, B.H., \& Patil, N.P. (2006). Bonding acrylic teeth to acrylic resin denture bases: a review. Gerodontology, 23(3), 131-139.

8. Leggat, P. A., Kedjarune, U., \& Smith, D. R. (2004). Toxicity of cyanoacrylate adhesives and their occupational impacts for dental staff. Industrial health, 42(2), 207-211.
9. Saavedra, G., Valandro, L. F., Leite, F. P. P., Amaral, R., Özcan, M., Bottino, M. A., \& Kimpara, E. T. (2007). Bond strength of acrylic teeth to denture base resin after various surface conditioning methods before and after thermocycling. International Journal of Prosthodontics, 20(2).

10. Sano H, S. T. (1994). Relationship between surface area for adhesion and tensile bond strength--evaluation of a micro-tensile bond test. Dental Materials , 10(4), 236-240.

11. Takahashi, Y., Chai, J., Takahashi, T., \& Habu, T. (2000). Bond strength of denture teeth to denture base resins. International journal of Prosthodontics, 13(1).

12. Wiebelt, F. J., Duncanson Jr, M. G., \& Stratton, R. J. (1982). Comparison of bond strengths of polymethyl methacrylate and alpha-cyanoacrylate. The Journal of prosthetic dentistry, 47(6), 603-605.

13. Cetin, A. R., Unlu, N., \& Cebe, M. A. (2013). Effects of ageing on the bond strength of self-etching adhesives and resin luting cements. Journal of Dental Sciences, 8(1), 61-67. 